Copyright (C) 2015 by Academic Publishing House Researcher

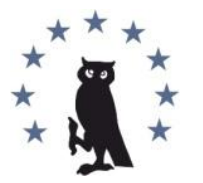

Published in the Russian Federation

European Researcher

Has been issued since 2010.

ISSN 2219-8229

E-ISSN 2224-0136

Vol. 9o, Is. 1, pp. 32-36, 2015

DOI: 10.13187/er.2015.90.32

www.erjournal.ru

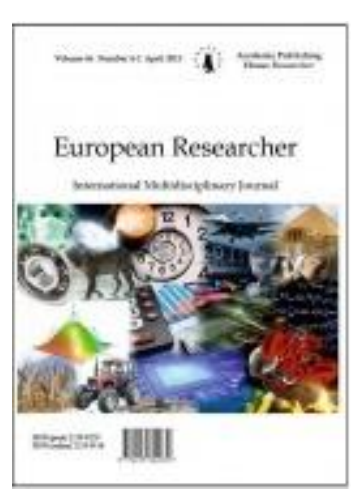

UDC 33

\title{
Efficiency Evaluation of Research Groups Using Data Envelopment Analysis
}

\author{
Ehssan Jandaghi
}

Iran University of Science and Technology, Tehran, Iran

E-mail: essanj@gmail.com

\begin{abstract}
The purpose of this study is to evaluate and compare efficiency of research groups in the Center of Social and Cultural Research. There are several tools for efficiency evaluation. The method used in this study was Data Envelopment Analysis (DEA) in which rate of output is evaluated by input and effective and non-effective units are determined. The first step in DEA is to prepare a list of inputs and outputs. The inputs in this study were personnel and administrative costs, the ratio of group staff to the total staff of the center and person-hours of labor. The outputs of this study contained the number of finished research projects, proportion of allocated budget to the total budget issued and the Percent of the projects' progress. The survey was carried out in 20 research groups, using DEA method. The analysis indicated that 5 groups were efficient and 3 groups were on border line. To improve non-efficient groups and converting them to efficient ones, we suggest some adjustments in inputs and outputs.

Keywords: Efficiency Evaluation; Data Envelopment Analysis; Constant Return to Scale, Variable Return to Scale.

\section{Introduction}

In today world, one of the ideal managers' thoughts in different sections is to gather and categorize information as well as to use analyzed information rightly to document managerial affairs [1]. Success in competition market needs a high level of performance via improvement of actions. To increase the competition advantage, must be aware of the strength, weakness, opportunities and threats to be able to make the best decision and have the best performance [2]. In recent years, with increasing the number of economic, cultural and social research centers, a very close competition in presentation of production and services has been aroused and due to limitation in resources, reduction in costs and increase in efficiency and effectiveness has been the main concern for managers [3].

Such concern has increased the needs for specialized research in the area of culture and society. The Center of Social and Cultural Research with this mission has begun its activities. Therefore it needs a continuous feedback which shows the importance of performance evaluation. The performance evaluation of the research groups and the continuous comparison with each other causes the improvement in research group and ultimately the research center. Due to different productions and services in the center, the performance evaluation seems a complex task. The Data Envelopment Analysis technique with its strong ability makes this evaluation possible to compare the efficiency of the research groups with different productions and services. In this technique, a
\end{abstract}


number of inputs and outputs will be utilized to evaluate the groups via a linear programming approach. This study aims to answer the following questions:

A. What are the appropriate input criteria for evaluation the research groups in the center? center?

B. What are the appropriate output criteria for evaluation the research groups in the

C. Which groups are more efficient?

D. What can be done to covert the non-efficient groups to efficient ones?

\section{Literature review}

Efficiency is a management concept with a long history, running from scientific management to business process reengineering. In the early 2oth century Harrington Emerson, an engineer, argued that an efficient organization was a necessary prerequisite to task and process efficiency. Rejecting the machine metaphor of scientific management, Emerson conceived of an organic organization where efficiency was a natural occurrence, not an imposed set of targets and procedures - a concept that has a lot in common with total quality management and a management philosophy that remains valid and important [4]. Efficiency is defined as the comparison of what is actually produced or performed with what can be achieved with the same consumption of resources (money, time, labor, etc.)[5]. In order to measure the efficiency of an organization, one must consider its performance and by an appropriate feedback try to make a continuous improvement. In recent years, different models have been presented for measuring the efficiency of educational and research centers. These models can be categorized in to two main groups. The soft models are based on qualitative data (Analytic Hierarchy Analysis-Delphi) and the hard models are based on the quantitative data (Data Envelopment Analysis - Operations Research) [6]. Many Researchers have used DEA model to evaluate the performance in decision making units (DMU). Jandaghi et al used DEA to evaluate efficiency of private and public hospitals in Qom province of Iran [7]. Tseng and Lee (2009) used DEA/AHP model to evaluate the importance of relation between drivers of human resources and variables of organizational performance. Thus, they have studied 129 companies in Taiwan and 112 companies in china in electronics industry. In this study, 5 human variable and 7 organizational performance variables are taken into consideration. The results indicate that the staffs request to participate in organizational activities has been observed in both Taiwanese and Chinese companies and the importance of staffs relationship in logical and hierarchical culture is more than one in developmental and participative cultures [8]. Costa (2012) employs intellectual capital approach to assess efficiency and productivity and determines best methods for implementing strategies of intellectual capital management. To do so, he employs data envelopment analysis and Malmquiest productivity indicator. The research represents two scientific and practical insights that can be used manage strategic and operational intellectual capitals. The results suggest efficient companies' instructions for progress [9]. Kuah et al. (2012) have conducted a research to offer a model for a gauging the performance of knowledge management in random setting. Hence, data envelopment analysis, Mont-Carlo stimulation and genetics algorithm have been used. Suggesting a comprehensive model of knowledge management, they prove the accuracy of model data through genetics algorithm, assess the efficiency of knowledge management and its process through MontCarlos data envelopment analysis and at last use the suggested model to evaluate the performance of knowledge management in higher education. The results of their model have been used to determine future strategies of knowledge management by managers [10]. Andrejić et al. (2012) have developed and suggested a DEA model for grouping the productivity of distribution centers that can help the managers to decide and increase productivity. Therefore, they have employed PCA-DEA and analyzed the performance of distribution centers of a commercial company in Serbia. According to various indicators used for evaluating efficiency, PCA has been used to filter indicators and DEA is used to evaluation the productivity [11]. Wu and $\mathrm{Wu}$ (2010) have evaluated the performance of e-banking through merging PCA/DEA. They have collected data by using recorded reports of main banks of the USA and the UK in two groups of financial and nonfinancial. Finally they show that bank staffs are the most important evaluation variable causing the higher bank returns [12]. 


\section{Methodology}

Data envelopment analysis was introduced first by Charnes, Cooper and Rhodes. This technique was a non-parametric method. That is used to make a production possibility set for evaluating the efficiency of decision- making units with various inputs and outputs and relatively evaluates them. This set indicates the maximum output which is determined by a certain input in efficient decision making units [13]. Some observations express outputs level and inputs combinations are required to make production possibility set. Hence, an efficient unit is defined as the one being able to make the maximum output by a certain input [14].

The first DEA model was introduced by Charnes et al. in 1978, and it was called CCR. Due to this point that in CCR the return to scale is assumed fixed while developing DEA, Banker et al. in 1984 developed CCR and return to scale assumed variable. This model was named BCC because Banker, Charnes and Cooper present it [15]. In this study input-oriented BCC is used to evaluate the performance which is indicated as follow:

$$
\begin{gathered}
E_{p}=\operatorname{Max} \frac{\sum_{r=1}^{s} u_{r} y_{r p}}{\sum_{i=1}^{m} V_{i} X_{i p}} \\
x: \frac{\sum_{r=1}^{s} u_{r} y_{r j}}{\sum_{i=1}^{m} V_{i} X_{i j}} \leq 1
\end{gathered}
$$

$$
\begin{aligned}
& \mathrm{i}=1,2, \ldots, \mathrm{m} \\
& j=1,2, \ldots g N \\
& r=1,2, \ldots, S \\
& u_{r}, V_{i} \geq 0
\end{aligned}
$$

In this research, the statistical population consists of all research groups in the Center of Social and Cultural Research. There were 20 research groups which were considered as our DMUs. The data belongs to the second half of year 2014. The input variables were administrative and personnel costs, the proportion of the group's staff to the total staff and person-hour engagement in the projects. The output variables were the proportion of finished project to the total projects in the group, the proportion of consumed budget to the total proposed budget and the percent of the project's progress.

Therefore we have 3 inputs and 3 outputs which satisfy the condition of utilization of DEA in which the number of DMUs must be at least two times the number of inputs and outputs. The analysis was done using the Frontier Software 4.2.0.

\section{Results}

After collecting the required data, the inputs and outputs were inserted in the Frontier Software. DEA just deals with data performance evaluation, also efficient value is used for ranking inefficient units. The results are shown in table 1.

Table1: Relative Efficiency of Research Groups

\begin{tabular}{|c|c|c|c|c|c|c|c|}
\hline $\begin{array}{c}\text { Researc } \\
\text { h Group }\end{array}$ & Score & $\begin{array}{c}\text { Efficienc } \\
\mathbf{y}\end{array}$ & Condition & $\begin{array}{c}\text { Researc } \\
\text { h Group }\end{array}$ & Score & $\begin{array}{c}\text { Efficienc } \\
\mathbf{y}\end{array}$ & Condition \\
\hline G1 & $\begin{array}{c}100.0 \\
\%\end{array}$ & $\sqrt{ }$ & Efficient & G11 & $79.2 \%$ & & $\begin{array}{c}\text { Non- } \\
\text { Efficient }\end{array}$ \\
\hline G2 & $95.1 \%$ & Border Line & G12 & $\begin{array}{c}100.0 \\
\%\end{array}$ & $\sqrt{ }$ & Efficient \\
\hline G3 & $78.7 \%$ & $\begin{array}{c}\text { Non- } \\
\text { Efficient }\end{array}$ & G13 & $83.9 \%$ & & $\begin{array}{c}\text { Non- } \\
\text { Efficient }\end{array}$ \\
\hline G4 & $84.9 \%$ & $\begin{array}{c}\text { Non- } \\
\text { Efficient }\end{array}$ & G14 & $\begin{array}{c}100.0 \\
\%\end{array}$ & $\sqrt{ }$ & Efficient \\
\hline
\end{tabular}




\begin{tabular}{|c|c|c|c|c|c|c|c|} 
G5 & $76.4 \%$ & $\begin{array}{c}\text { Non- } \\
\text { Efficient }\end{array}$ & G15 & $95.8 \%$ & & Border Line \\
\hline G6 & $65.7 \%$ & $\begin{array}{c}\text { Non- } \\
\text { Efficient }\end{array}$ & G16 & $\begin{array}{c}100.0 \\
\%\end{array}$ & $\sqrt{ }$ & Efficient \\
\hline G7 & $57.6 \%$ & $\begin{array}{c}\text { Non- } \\
\text { Efficient }\end{array}$ & G17 & $96.4 \%$ & Border Line \\
\hline G8 & $58.0 \%$ & $\begin{array}{c}\text { Non- } \\
\text { Efficient }\end{array}$ & G18 & $39.1 \%$ & $\begin{array}{c}\text { Non- } \\
\text { Efficient }\end{array}$ \\
\hline G9 & $82.7 \%$ & $\sqrt{\text { Non- }}$ & G19 & $43.8 \%$ & $\begin{array}{c}\text { Non- } \\
\text { Efficient }\end{array}$ \\
\hline G10 & $\begin{array}{c}100.0 \\
\%\end{array}$ & $\sqrt{ }$ & Efficient & G20 & $63.0 \%$ & & $\begin{array}{c}\text { Non- } \\
\text { Efficient }\end{array}$ \\
\hline
\end{tabular}

As Table 1 Shows, five research groups (G1, G10, G12, G14 and G16) were recognized as efficient groups (G2, G15 and G17). Three groups have borderline efficiency and the other groups have a far different to the borderline efficiency.

Figure 1: Percent Change Required to make the groups efficient

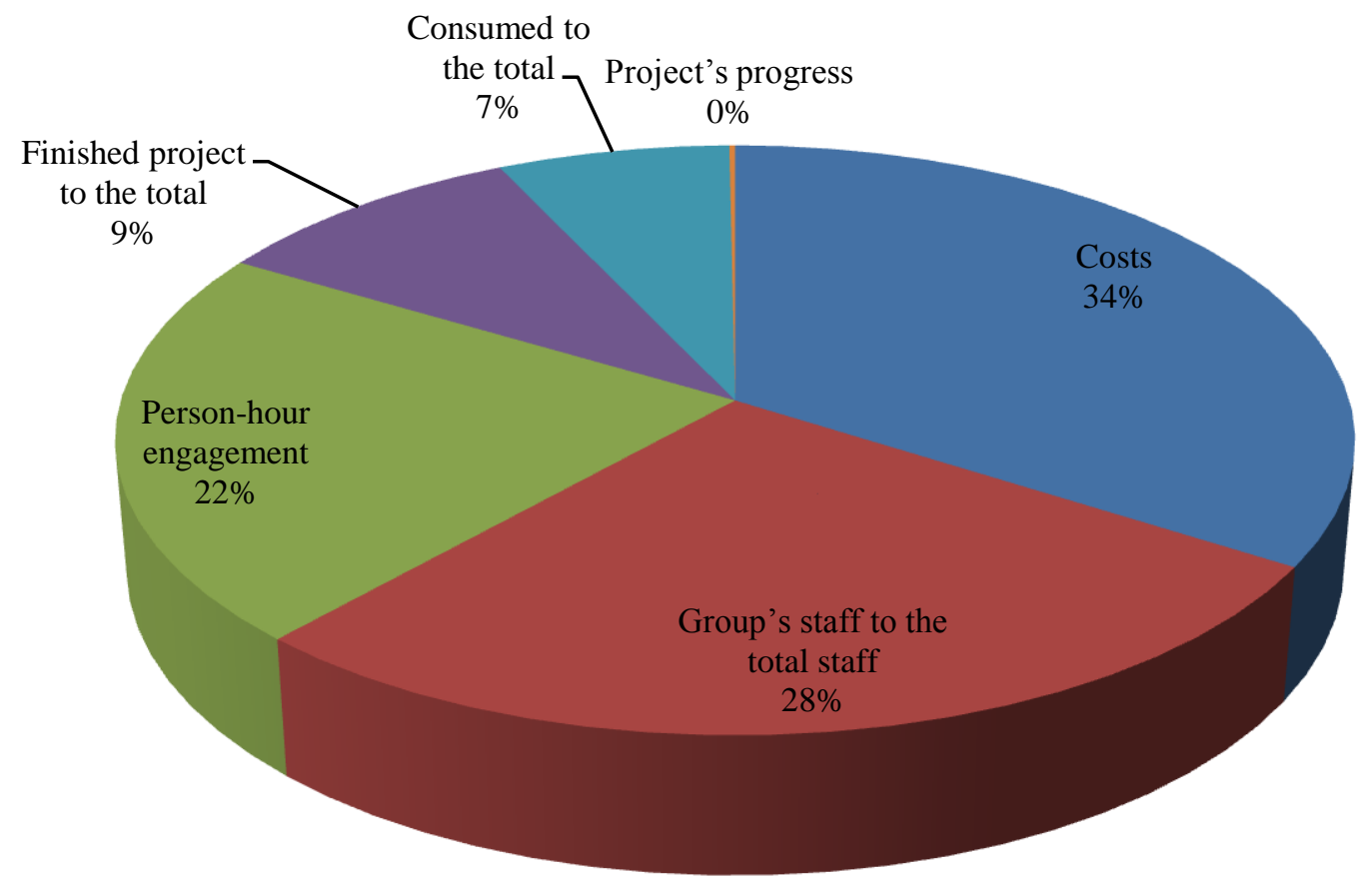

\section{Discussion and Conclusion}

Different Research using DEA techniques show that this method has some strong merits in performance and efficiency evaluation. Due to the important role of research centers in social and cultural studies, the investigation of the quality and performance of such centers is a vital stage in the continuous improvement of them. In the present study, the results of the analyses shows the 
required modification and changes in the inputs and outputs. In inputs, the most concerns must be taken into account are the administrative and personnel costs and the proportion of the group's staff to the total staff. As shown in Figure 1, there is a strong relationship between the administrative and personnel costs and the proportion of the group's staff to the total staff which indicates that one of the options in the organization is reducing the number of personnel. This change will reduce the administrative and personnel costs. In outputs, the notice should be paid to the proportion of finished projects to the total projects and the proportion of consumed budget to the total proposed budget. It is suggested that the center sets up a control project system and a cyclic evaluation of the projects. This system forces more progress in doing projects and total performance increases.

\section{References}

1. Dadgar Y. (2007), Applying DEA in analyzing Iranian economy (Tejarat Bank Districts), Iran's Economic Essays, 4(7): 11-54.

2. Mehregan M. (2004) Quantitative Models for Performance Evaluation in Organizations, University of Tehran Press.

3. Shahriari S. (2003) Presenting a DEA Model for Relative Performance Evaluation in Human Science Schools of University of Tehran, M.Sc. Thesis, University of Tehran, Iran

4. Witzel M. (2002) A Short History of Efficiency, Business Strategy Review, 13: 38-47.

5. http://www.businessdictionary.com

6. Azar A., Torkashvand A. (2006) Evaluation of Education and Research by DEA, Modares Journal, 10:1-23.

7. Jandaghi Gh., Zarei Matin H. Doremami M., Aghaziarati M. (2010) Efficiency Evaluation of Qom Public and Private Hospitals Using Data Envelopment Analysis, European Journal of Economics, Finance and Administrative Sciences, 22:83-92.

8. Tseng Y. and Lee T. (2009) Comparing appropriate decision support of human resource practices on organizational performance with DEA/AHP model, Expert Systems with Applications, 36 (3): 6548-6558.

9. Costa R. (2012) Assessing Intellectual Capital efficiency and productivity: An application to the Italian yacht manufacturing sector, Expert Systems with Applications, 39 (8):7255-7261.

10. Kuah C. T., Wong K. Y. and Wong W. P. (2012) Monte Carlo Data Envelopment Analysis with Genetic Algorithm for Knowledge Management performance measurement, Expert Systems with Applications, 39 (10):9348-9358.

11. Andrejić, M., Bojović N. and Kilibarda M. (2013) Benchmarking distribution centers using Principal Component Analysis and Data Envelopment Analysis: A case study of Serbia, Expert Systems with Applications, In Press, (2013).

12. Wu D. and Wu D. D. (2010) Performance evaluation and risk analysis of online banking service, Kybernetes, 39(5):723-734.

13. Shen Y., Hermans E., Brijs T., Wets G. and, Vanhoof K. (2012), Road safety risk evaluation and target setting using data envelopment analysis and its extensions, Accident Analysis and Prevention, 48 (1):430-441.

14. Charnes A., Cooper W. W., Lewin A. Y. and Seiford L. M. (1995) Data Envelopment Analysis: Theory, Methodology and Applications, Kluwer Academic Publishers, Boston.

15. Charnes A., Cooper W. W. and Rhodes E. (1978) Measuring the Efficiency of Decision Making Units, European Journal of Operational Research, 2 (6):429-444. 